\title{
Stemness Signature of Equine Marrow-derived Mesenchymal Stem Cells
}

\author{
Morteza Zahedi ${ }^{1}$, Abbas Parham ${ }^{1,2}$, Hesam Dehghani, ${ }^{1,2}$, Hossein Kazemi Mehrjerdi ${ }^{3}$ \\ ${ }^{I}$ Division of Physiology, Department of Basic Sciences, Faculty of Veterinary Medicine, Ferdowsi University of Mashhad, Mashhad, Iran, \\ ${ }^{2}$ Embryonic and Stem Cell Biology and Biotechnology Research Group, Institute of Biotechnology, Ferdowsi University of Mashhad, \\ Mashhad, Iran, ${ }^{3}$ Department of Clinical Sciences, Faculty of Veterinary Medicine, Ferdowsi University of Mashhad, Mashhad, Iran
}

Background: Application of competent cells such as mesenchymal stem cells (MSCs) for treatment of musculoskeletal disorders in equine athletes is increasingly needed. Moreover, similarities of horse and human in size, load and types of joint injuries, make horse as a good model for MSCs therapy studies. This study was designed to isolate and characterize stemness signature of equine bone marrow-derived mesenchymal stem cells (BM-MSCs).

Methods: BM of three mares was aspirated and the mononuclear cells (MNCs) were isolated using density gradient. The primary MNCs were cultured and analyzed after tree passages (P3) for growth characteristics, differentiation potentials, and the expression of genes including CD29, CD34, CD44, CD90, CD105, MHC-I, MHC-II and pluripotency related genes (Nanog, Oct-4, Sox-2, SSEA-1, -3, -4) using RT-PCR or immunocytochemistry techniques.

Results: The isolated cells in P3 were adherent and fibroblast-like in shape with doubling times of $78.15 \mathrm{~h}$. Their clonogenic capacity was $8.67 \pm 4 \%$ and they were able to differentiate to osteogenic, adipogenic and chondrogenic lineages. Cells showed expression of CD29, CD44, CD90, MHC-I and Sox-2 while no expression for CD34, MHC-II, CD105, and pluripotency stemness markers was detected.

Conclusions: In conclusion, data showed that isolated cells have the basic and minimal criteria for MSCs, however, expressing only one pluripotency gene (sox-2).

Keywords: Mesenchymal stem cells, Bone marrow, Equine, Pluripotency, Stemness markers

\section{Introduction}

Most of degenerative diseases including spinal cord, musculoskeletal, and tendon lesions are not repairable

\footnotetext{
Accepted for publication October 15, 2016, Published online May 30, 2017 Correspondence to Abbas Parham

Division of Physiology, Department of Basic Sciences, Faculty of Veterinary Medicine \& Institute of Biotechnology, Ferdowsi University of Mashhad, Mashhad 91779-48974, Iran

Tel: +98-51-38805600, Fax: +98-51-38805600

E-mail: Parham@um.ac.ir

(c) This is an open-access article distributed under the terms of the Creative Commons Attribution Non-Commercial License (http://creativecommons.org/ licenses/by-nc/4.0/), which permits unrestricted non-commercial use, distribution, and reproduction in any medium, provided the original work is properly cited.

Copyright (c) 2017 by the Korean Society for Stem Cells Research
}

with the routine methods, due to loss of tissue cellular content and inability to replace them (1). Musculoskeletal disorders in equine athletes have a major influence on equine performance, and are the main reason for financial loss in racing industry (2). Fast and full recovery of chronic musculoskeletal disorders and returning to race is of primary importance. New hopes have been raised by improvement in stem cell research field to treat these kinds of incurable equine diseases. To date, there are several studies that show the application of different types of stem cells in the treatment of equine musculoskeletal disorders $(3,4)$.

Furthermore, suitability of horse as an animal model for human studies in musculoskeletal disorders, especially in cartilage and tendon injuries has been previously emphasized $(5,6)$. The characteristics of horse joint and carti- 
lage, including size, anatomy, and morphology of the joints, the thickness and composition of cartilage, and low intrinsic capability for repair are similar to those in human (5-7). In addition, the hierarchical structure, matrix composition, the function and the nature of the injuries of weight-bearing tendons (e.g. Achilles tendon) in the human athlete and horse have many similarities (8). On the other hand, the homology of equine immune system proteins to human ones is about $60 \sim 98 \%$ (9). Moreover, regeneration techniques applicable to human may need validation in a large animal model. A report from U.S. Food and Drug Administration (FDA) has also concluded that the horse is the most appropriate animal model for testing and analyzing the clinical effects of mesenchymal stem cell (MSC)-based therapies for joint injuries in human due to similarities in size, load and types of joint injuries (10).

Complete identification and stemness signature of adult stem cells, in particular MSCs, is the first critical step for their clinical application. MSCs can be obtained from different tissues such as bone marrow (BM) stroma, periosteum, umbilical cord blood, fat, and skin (11). Despite of isolation of equine MSCs from many tissues, bone marrow is the most common source and it is the most investigated source. It has been proven that these multipotent cells are able to differentiate to cartilage, muscle, tendon, ligament, fat and also some other type of cells such as neurons and hepatocytes which show their pluripotent capacity (12). In addition, it has been reported that MSCs are hypoimmunogenic and immunomodulator and escape from allogeneic rejection (13) and can be used for allogeneic cell therapy. Evidence show that transplantations of allogeneic MSCs have therapeutic effects similar to autologous transplantation (14).

Although some studies have identified the characteristics of equine MSCs, some of their features, in particular the expression of embryonic stemness markers and their multipotency or pluripotency abilities are not completely shown $(3,15)$. De Schauwer et al. (3) has determined minimal criteria for identification of equine MSCs: 1) adherence to the plastic culture dish in normal condition, 2) expression of surface antigens CD29, CD44 and CD90 and no expression of CD14, CD79 $\alpha$, and MHC-II, and 3) in vitro differentiation to three kinds of cells (osteoblasts, chondrocytes and adipocytes) under standard differentiation conditions. Expression of Oct4, SSEA-3, SSEA-4, Nanog and Tra-1-60 (as embryonic stem cell markers) has been shown in some studies (16-20), while some others have reported negative results (15). There are some reports that MSCs are able to differentiate into various cell types of non-mesodermal lineages such as hepatocytes (21) in rat, neuron in mice, and epithelial and endothelial cells in human (22). Thus, it has been suggested that MSCs are in mid-stage between pluripotent embryonic stem cells and lineage-restricted adult stem cells and have a great capacity for differentiation.

Therefore, this study aimed to isolate and characterize equine BM-MSCs and to identify their growth features, differentiation potentials and gene expression profile including embryonic stemness markers (SSEA-1, SSEA-3, SSEA-4, Nanog and Sox-2).

\section{Materials and Methods}

The experiment protocol was approved by Animal Welfare Committee of Veterinary faculty, Ferdowsi University of Mashhad, Iran. All the reagents were provided by Sigma-Aldrich (Germany) company, except for those which are mentioned later on. All the culture dishes and polypropylene tubes were purchased from SPL (Korea).

\section{Sample Collection and Cell Culture}

Bone Marrow Aspiration: Bone marrow (BM) was aspirated from 3 healthy crossbreed mares, aged 6,9 and 10 years old. To strain horse, xylazine $(0.5 \mathrm{mg} / \mathrm{kg})$ was injected intravenously and aspiration location in sternum was determined by ultrasonography. Then, $10 \mathrm{ml}$ of lidocaine with adrenalin was used in the aspiration area for local anesthesia. Using a surgery knife, a surface cut made and by Jamshidi needle (gauge 13 and $100 \mathrm{~mm}$ length) $10 \sim 15 \mathrm{ml}$ of bone marrow was aspirated into a $20 \mathrm{ml}$ syringe which contained $1000 \mathrm{IU} / \mathrm{ml}$ heparin. The samples, in less than 4 hours, were carried on ice to the laboratory.

Cell Isolation and Culture: In laboratory and in sterilized condition, the BM samples were diluted by basal medium (DMEM-HG, 10\% FBS, 1\% Penicillin-Streptomycin and $0.1 \%$ Amphotericin B) twice the volume of the samples. Then, it was gently poured onto density gradient media (Histopaque ${ }^{\circledR}$ 1077) to the ratio of 2:1. The tubes containing samples were centrifuged at $400 \mathrm{~g}$ in $4^{\circ} \mathrm{C}$ for 30 min (in brake off mode). Afterwards, monolayer nucleated cells (MNCs) were carefully gathered and rinsed twice by Dulbecco's Phosphate Buffer Saline (DPBS-) by centrifugation in $600 \mathrm{~g}$ in $4^{\circ} \mathrm{C}$ for $5 \mathrm{~min}$. The final cell pellet was diluted in $4 \mathrm{ml}$ basal medium and cell population was counted using Neubauer counting chamber. Then, cells were cultured at the density of $8 \times 10^{5} \mathrm{cells} / \mathrm{cm}^{2}$ as the primary culture or passage $0(\mathrm{P} 0)$ in $37^{\circ} \mathrm{C}$ humidified atmosphere containing $5 \% \mathrm{CO}_{2}$ condition. Culture 
medium was replaced with fresh medium every 3 days. At confluency of $80 \sim 90 \%$, cells came into passage 1 (P1) using trypsinization where the cells were seeded at the density of $5 \times 10^{3}$. Similar process was conducted until passages 3 (P3). P3 cells were collected for the next experiments.

\section{Growth Characteristics}

Growth Curve: In order to assess cell growth rate, the cells were seeded at $3 \times 10^{4}$ cells/well in 2 twelve-well plates. Every 24 hours, the cell numbers of 3 wells were counted and the mean was calculated until $8^{\text {th }}$ day and the growth curve was drawn based on the gathered data.

Colony Forming Unit-Fibroblast (CFU-F) and Plating Efficiency (PE): For colony formation evaluation, $5 \times 10^{2}$ cells were seeded in each well of a six-well plate. Every 3 days the mediums were changed and after 12 days, culture medium was discarded and the cells were rinsed with PBS. The colonies were then stained by $0.5 \%$ Crystal Violet for $10 \mathrm{~min}$. Afterwards, the wells were rinsed by tap water and the colonies containing over 15 cells were counted under invert microscope. The following formula was utilized to determine the plating efficiency:

Plating efficiency $=$ the number of colonies/the number of seeded cells $\times 100$

Cell Population Doubling Time: In each of the passages, the number of cells was recorded in the beginning and the end of passage. In order to calculate the proliferation of cells per day, the following formula was used, where $\mathrm{N}_{\mathrm{i}}=$ indicates initial seeded cells, $\mathrm{N}_{\mathrm{f}}$ is the harvested cell number, CT is the culture time, PD is cell population doubling per day and DT shows the proper time for doubling cells (hours).

$$
\begin{aligned}
& C D=\frac{\log \left(\frac{N f}{N i}\right)}{\log 2} \\
& P D=C D / C T \\
& D T=C T / C D
\end{aligned}
$$

\section{Characterization of Mesenchymal Stem Cells}

Trilineage differentiation potential: P3 cells of all 3 mares were used for trilineage differentiation.

Osteogenic differentiation: $3 \times 10^{5}$ cells were seeded in 3 wells of a six-well plate. At 50\% confluency, basal medium was discarded and two of them were replaced with osteogenic medium (basal medium supplemented with 0.1 $\mu \mathrm{M}$ dexamethasone, $10 \mathrm{mM} \beta$-Glycerophosphate disodium salt hydrate and $50 \mu \mathrm{M}$ 2-Phospho-L-ascorcbic acid trisodium salt) and the remaining one was left unchanged as control. The media were changed every 3 days. After 21 days, the cells were fixed with $10 \%$ neutral buffered formalin and then stained using 2\% Alizarian Red S in order to analyze differentiation.

Adipogenic differentiation: $3 \times 10^{5}$ cells were cultured in three wells of a six-well plate. After $80 \%$ confluency, the medium was discarded and two of the wells were replaced with adipogenic medium (basal medium supplemented with $0.1 \mu \mathrm{M}$ dexamethasone, $100 \mu \mathrm{M}$ indomethacin, 500 $\mu \mathrm{M}$ 3-isobutyl-1- methyl xanthine, 1\% Insulin-Transferrin-selenium-X) and the other one was replaced with basal medium. Every 3 days the mediums were changed until the $21^{\text {st }}$ day, on which the wells were rinsed by PBS, fixed and stained by fresh Oil Red $\mathrm{O}$ to determine adipogenic differentiation.

Chondrogenic differentiation: $5 \times 10^{5}$ cells were transferred into each of the $15-\mathrm{ml}$ polypropylene conical Falcon tubes, and then centrifuged at $260 \mathrm{~g}$ for $5 \mathrm{~min}$ (at room temperature). Supernatant was discarded and $2 \mathrm{ml}$ basal medium added to the falcons and let them to adapt for 24 hours. The following day, basal medium was substituted with chondrogenic differentiation medium (basal medium supplemented with $0.1 \mu \mathrm{M}$ dexamethasone, 50 $\mu$ M 2-Phospho-L-ascorcbic acid trisodium salt, $10 \mathrm{mM}$ $\beta$-Glycerophosphate disodium salt hydrate, $1 \mathrm{mg} / \mathrm{ml}$ Bovine Serum Albumin (BSA), $10 \mathrm{ng} / \mathrm{ml}$ human Transforming Growth Factor- $\beta 3$ (TGF- $\beta 3$ ) and $10 \mathrm{ng} / \mathrm{ml}$ Bone Morphogenetic Protein-6 (BMP6)) for the treated group and basal medium was added to the control group wells. The mediums of each group were replaced with fresh ones every four days until the end of culture (21 days). Afterwards, the pellets were stained by Alician Blue for histological examination.

\section{Gene expression profiling}

\section{Reverse Transcription - Polymerase Chain Reaction (RT-PCR)}

RNA Extraction and cDNA synthesis: Total RNA of cells was extracted by DenaZist kit (Iran) under the manufacture protocol. Briefly, each sample was lysed and homogenized in $1 \mathrm{ml} \mathrm{Gl}$ buffer. The homogenate was incubated at room temperature $\left(20^{\circ} \mathrm{C}\right)$ for 10 minutes. Then, $200 \mu 1$ chloroform was added and sample was centrifuged at $12,000 \mathrm{~g}$ for $15 \mathrm{~min}$ at $4^{\circ} \mathrm{C}$ and upper phase containing RNA was precipitated with equivalent of half the volume aqueous phase of the isopropyl alcohol and the same volume from G2 buffer. Afterwards washing was performed 
by $75 \%$ ethanol and sample was dried in contact with air, and resuspended in diethyl pyrocarbonate (DEPC)-treated water. In order to remove any possible genomic DNA, five unit RNase free DNAse I (Roche, Germany) was added per each $20 \mu \mathrm{g}$ of RNA and incubated at $34^{\circ} \mathrm{C}$ for $20 \mathrm{~min}$ followed by adding $0.8 \quad \mu 10.5 \mathrm{M}$ EDTA and heat inactivation of the enzyme at $75{ }^{\circ} \mathrm{C}$ for $10 \mathrm{~min}$. RNA concentration, purity and quality were appraised using NanoDrop 2000 (Thermo Scientific, USA) and gel electrophoresis. Then cDNA was synthesized by AccuPower ${ }^{\circledR}$ RT Premix kit (Bioneer, USA). $1 \mu \mathrm{g}$ of RNA was mixed with $0.5 \mu \mathrm{g}$ Oligo(dT) ${ }_{18}$ Primer (Fermentas, USA) and it was added to the kit, then reached $20 \mu 1$ using diethyl pyrocarbonate (DEPC)-treated water. The kit was incubated at $42^{\circ} \mathrm{C}$ for $60 \mathrm{~min}$ and finally at $70^{\circ} \mathrm{C}$ for $10 \mathrm{~min}$ to deactivate reverse transcriptase enzyme.

Polymerase Chain Reaction (PCR): Specific primers of GAPDH, CD29, CD34, CD44, CD90, CD105, Sox-2, Oct-4 and Nanog genes were designed based on the available sequences in GeneBank (NCBI) using Primer Premier software (PREMIER Biosoft International, USA) (Table 1). Glyceraldehyde-3-phosphate dehydrogenase (GAPDH) used as internal control.

PCR was performed in $25 \mu 1$ final volume with tag polymerase enzyme (Pars Tous, Iran) at the following con- dition: initial denaturation at $95^{\circ} \mathrm{C}$ for $5 \mathrm{~min}, 30$ cycles at $95^{\circ} \mathrm{C}$ for $30 \mathrm{~s}$ (denaturation), $51 \sim 61^{\circ} \mathrm{C}$ for $45 \mathrm{~s}$ (annealing for different primers), $72^{\circ} \mathrm{C}$ for $1 \mathrm{~min}$ (elongation) and final extension at $72^{\circ} \mathrm{C}$ for $10 \mathrm{~min}$, and then cooling to room temperature. PCR products were visualized with ethidium bromide (Cinnagen, Iran) on a $1.5 \%$ agarose gel (Cinnagen, Iran). A 100 bp DNA ladder (Fermentas, USA) used as marker to determine the size of amplified products.

Immunocytochemistry: To detect expression of some specific markers in isolated MSCs, immunocytochemistry method was performed. $6 \times 10^{4}$ undifferentiated cells at P3 were grown overnight on coverslips and then fixed with 4\% paraformaldehyde for $15 \mathrm{~min}$ at room temperature. Afterward cells were permeabilized with Triton X-100 diluted in PBS for $10 \mathrm{~min}$. After washing 3 times with PBS, endogenous peroxidases were blocked with 3\% $\mathrm{H} 2 \mathrm{O} 2$ (Merck, Germany) in PBS for $30 \mathrm{~min}$, then cells were incubated in $4 \%$ BSA in PBS for $1 \mathrm{~h}$ at room temperature to prevent the nonspecific binding of the antibodies. Coverslips were incubated overnight with different primary antibodies: Nanog (1:100, Santa Cruz Biotechnology, USA), SSEA-1 (1:100, Santa Cruz Biotechnology, USA), SSEA-3 (1:100, Abcam, USA) and SSEA-4 (1:100, Santa Cruz Biotechnology, USA) diluted in $1 \%$ BSA in PBS at

Table 1. Characteristics of primer pairs which were used in the experiment

\begin{tabular}{|c|c|c|c|c|}
\hline Gene & Accession Number & Primer Sequence & Annealing Temperature & Product Size (bp) \\
\hline Equine GAPDH & $\begin{array}{l}\text { NM_001163856 } \\
\text { NC_009149 }\end{array}$ & $\begin{array}{l}F^{\mathrm{a}}: \text { TGTCATCAACGGAAAGGC } \\
\mathrm{R}^{\mathrm{b}}: \text { GCATCAGCAGAAGGAGCA }\end{array}$ & 56 & $\begin{array}{l}\mathrm{CDNA}^{\mathrm{c}}=183 \\
\operatorname{gDNA}^{\mathrm{d}}=429\end{array}$ \\
\hline Equine CD29 & XM_001492665 & $\begin{array}{l}\text { F: AATCGGGACAAGTTACCTCA } \\
\text { R: CTTCCAAATCAGCAGCAAT }\end{array}$ & 56 & 234 \\
\hline Equine CD34 & XM_001491596 & $\begin{array}{l}\text { F: TGATGAATCGCCGTAGT } \\
\text { R: CGGGTTGTCTCGCTGA }\end{array}$ & 56 & $\begin{array}{l}\mathrm{cDNA}=204 \\
\mathrm{gDNA}=907\end{array}$ \\
\hline Equine CD44 & NM_001085435 & $\begin{array}{l}\text { F: AACCTCGGGTCCCATAC } \\
\text { R: TCCATTGAGCCCACTTGC }\end{array}$ & 56 & 193 \\
\hline Equine CD90 & XM_001503225 & $\begin{array}{l}\text { F: AGAATACCACCGCCACA } \\
\text { R:GGATAAGTAGAGGACCTTGATG }\end{array}$ & 51 & 155 \\
\hline Equine CD105 & XM_003364144 & $\begin{array}{l}\text { F: GACGCCAATCACAACATACA } \\
\text { R: TCCACATAGGACGCTACGAC }\end{array}$ & 60 & 158 \\
\hline Equine MHC-I & NM_001123381 & $\begin{array}{l}\text { F: CTGGGTCTCCCTGTCGTTG } \\
\text { R: CCTTGGGCACTGTCACTG }\end{array}$ & 56 & 110 \\
\hline Equine $\mathrm{MHC}-\mathrm{II}$ & NM_001142816 & $\begin{array}{l}\text { F: GGAACGGGCAGCAGGACAT } \\
\text { R: AAGCCATTCACAGAGCAGACCA }\end{array}$ & 56 & 184 \\
\hline Equine Sox-2 & XM_003363345 & $\begin{array}{l}\text { F: TGGACCAACGGAGGCTATG } \\
\text { R: CCCTTGCTGGGAGTACGAC }\end{array}$ & 56 & 198 \\
\hline Oct-4 & & $\begin{array}{l}\text { F: GTTGTCCGGGTCTGGTTCT } \\
\text { R: GTGGAAAGGTGGCATGTAGAC }\end{array}$ & 57 & 189 \\
\hline Nanog & & $\begin{array}{l}\text { F: CAGCAGACCTCTCCTTGACC } \\
\text { R: TTCСТTGTCССАСТСТСАСС }\end{array}$ & 55 & 187 \\
\hline
\end{tabular}

${ }^{\mathrm{a}} \mathrm{F}$ : Forward primer; ${ }^{\mathrm{b}} \mathrm{R}$ : Reverse primer; ${ }^{\mathrm{c} C D N A}$ : complementary DNA; ${ }^{\mathrm{d}} \mathrm{gDNA}$ : genomic DNA. 
$4^{\circ} \mathrm{C}$ in humid chamber. After washing 3 times, the cells were incubated $2 \mathrm{~h}$ with secondary $\operatorname{IgM}$ (Jackson Immunoresearch, USA) or IgG (Dianova, Germany) antibodies conjugated to horseradish peroxidase (HRP) diluted 1:500 in 1\% BSA in PBS. Reaction between antigen and antibody was visualized by 3,3'-Diaminobenzidine tetrahydrochloride hydrate (DAB) substrate. The NTERA2 (human testicular embryonic carcinoma cell line) was used as positive control for Nanog, SSEA-3, and SSEA-4 and P19 cells (cell line derived from a teratocarcinoma in mice) was used as positive control for SSEA-1.

\section{Results}

\section{Morphology of cultured cells}

MNCs containing MSCs were cultured as P0 at day 0. Dead or non-attachable cells were removed by the first medium change after 3 days in culture. The first colonies of MSCs were observed 4 days after MNCs seeding. The morphology of MSCs in colonies was heterogeneous and had spindle-shaped fibroblast-like, asteroid and triangular shape (Fig. 1A). In addition, considerable number of round-shaped cells were observed at P1 (Fig. 1B). At the end of P3, an almost homogeneous fibroblast-like population of MSCs was obtained (Fig. 1C) which was used for further analysis.

\section{Growth Characteristics}

Growth Curve: Growth curve of BM-MSCs showed an initial lag phase of 3 days, followed by an exponential phase for 3 days and then the cells were entered to plateau phase at the day 6 or 7 . On day 8 , the cell population im- mediately starts to decrease (Fig. 2).

Colony Forming Unit-Fibroblast (CFU-F) and Plating Efficiency (PE): Cultured MSCs in wells with density of $5 \times 10^{2}$ produced averagely $43.3 \pm 20.1$ colonies which show their colonogenic capability (Table 2). The mean percentage of PE BM-MSCs at the P3 was $8.67 \pm 4 \%$ and the details of different horses are also presented in Table 2.

Cell Population Doubling Time: $\mathrm{PD}(\mathrm{PD}=\mathrm{CD} / \mathrm{CT})$ of cells from 0.5 in passage 1 was decreased to 0.32 in passage 3. Consequently, the needed time for doubling of population (DT) were increased from 48.62 hours in passage 1 to 78.15 hours in passage 3 (Table 3).

Conformation of MSC characteristics: To identify the isolated cells as MSCs, their trilineage differentiation potentials and gene expression profiling were analyzed. In addition, the expression of embryonic stemness markers was investigated to clarify their potency.

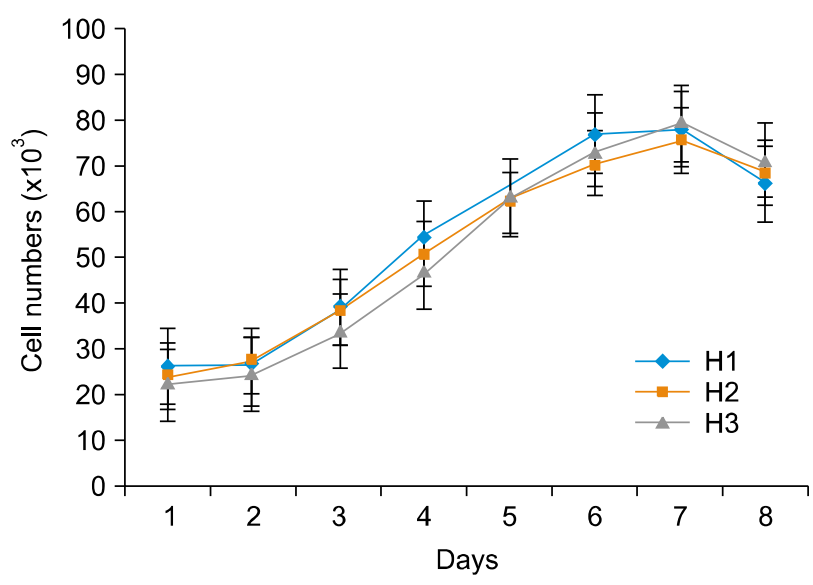

Fig. 2. The growth curve of the equine BM-MSCs at P3. Cells enter the 3 days of log phase after 3 days of lag phase, and reach the plateau phase at the day 6 or 7 .
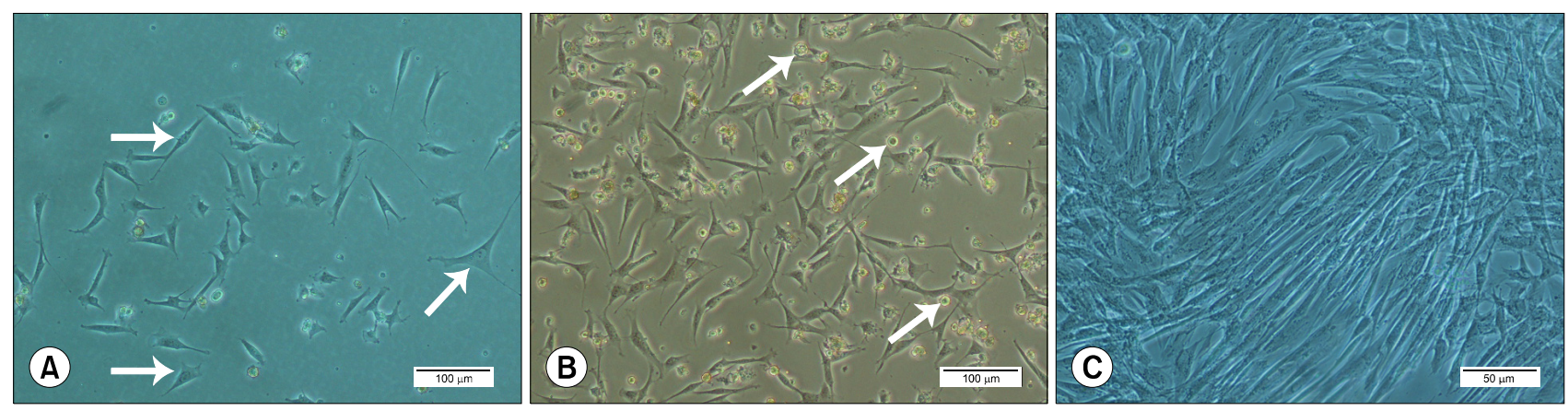

Fig. 1. The morphology of equine BM-MSCs. (A) Heterogeneous, spindle-shaped fibroblast-like, asteroid and, triangular shape of equine MSCs at P1. (B) Round-shape cells among fibroblast-like cells at early passages, and (C) almost homogeneous fibroblast-like population of equine MSCs at the end of P3. 


\section{Trilineage differentiation potential}

Osteogenic differentiation: The cultured cells after exposure to osteogenic inductive medium for 21 days, secreted and deposited extracellular calcium crystals which were identified by Alizarian Red S staining (Fig. 3A and 3B).

Adipogenic differentiation: Adipogenic differentiating inductive medium resulted in appearance of cytosolic lipid droplets after 21 days, which were identified and stained with Oil Red O staining (Fig. 3C).

Chondrogenic differentiation: Histological staining and analysis of extracellular-matrix proteoglycans with Alcian Blue showed chondrogenic differentiation in micropellets which were exposed to chondrogenic inductive medium

Table 2. Clonogenic capacity and mean of plating efficiency percentage ( $\mathrm{PE} \%$ ) of equine mesenchymal stem cells at passage 3

\begin{tabular}{lcc}
\hline & $\begin{array}{c}\text { Number of colonies } \\
(\text { mean } \pm \text { SD) }\end{array}$ & PE (\%) \\
\hline Cells from animal 1 & $49 \pm 24$ & $9.8 \pm 4.8$ \\
Cells from animal 2 & $42.3 \pm 15.3$ & $8.46 \pm 3$ \\
Cells from animal 3 & $38.6 \pm 21.2$ & $7.73 \pm 4.2$ \\
Total average & $43.3 \pm 20.1$ & $8.67 \pm 4$ \\
\hline
\end{tabular}

Plating efficiency was calculated as the percentage of colonies formed from the total number of seeded cells. for 21 days. The morphology of cells had changed from fibroblast-like cells to round cells within lacunae in treated groups (Fig. 3D).

In all trilineage differentiation assays, control groups were treated with basal growth medium without any additive inductive components (Fig. $3 \mathrm{E} \sim \mathrm{H}$ ).

\section{Gene expression profiling}

Expression of MSC marker genes at mRNA level: For RT-PCR analysis, GAPDH was used as internal control. GAPDH primers sets would amplify two fragments (183 bp and $429 \mathrm{bp}$ ) from genomic DNA, and only one fragment (183 bp) form cDNA. Hence, observation of only 183 bp amplicon in PCR products confirmed the absence of any DNA contamination in all samples. In addition, pri-

Table 3. Population doubling per day (PD) and doubling time (DT) for equine mesenchymal stem cells at passage 1 to 3

\begin{tabular}{lcccccccc}
\hline & \multicolumn{2}{c}{ Passage 1} & & \multicolumn{2}{c}{ Passage 2} & & \multicolumn{2}{c}{ Passage 3} \\
\cline { 2 - 3 } \cline { 7 - 8 } & PD & DT $^{\text {b }}$ & & PD & DT & & PD & DT \\
\hline $\mathrm{H}^{\text {a }}{ }^{n}$ & 0.52 & 47.10 & & 0.42 & 59.11 & & 0.32 & 76.51 \\
$\mathrm{H} 2$ & 0.47 & 51.22 & & 0.38 & 63.62 & & 0.38 & 64.16 \\
$\mathrm{H} 3$ & 0.51 & 47.54 & & 0.43 & 55.65 & & 0.26 & 93.79 \\
Mean & 0.50 & 48.62 & & 0.41 & 59.46 & & 0.32 & 78.15 \\
\hline
\end{tabular}

${ }^{\mathrm{a}} \mathrm{H} 1,2,3$ indicate different horses. ${ }^{\mathrm{b}} \mathrm{DT}$ was calculated as hours at each passage.
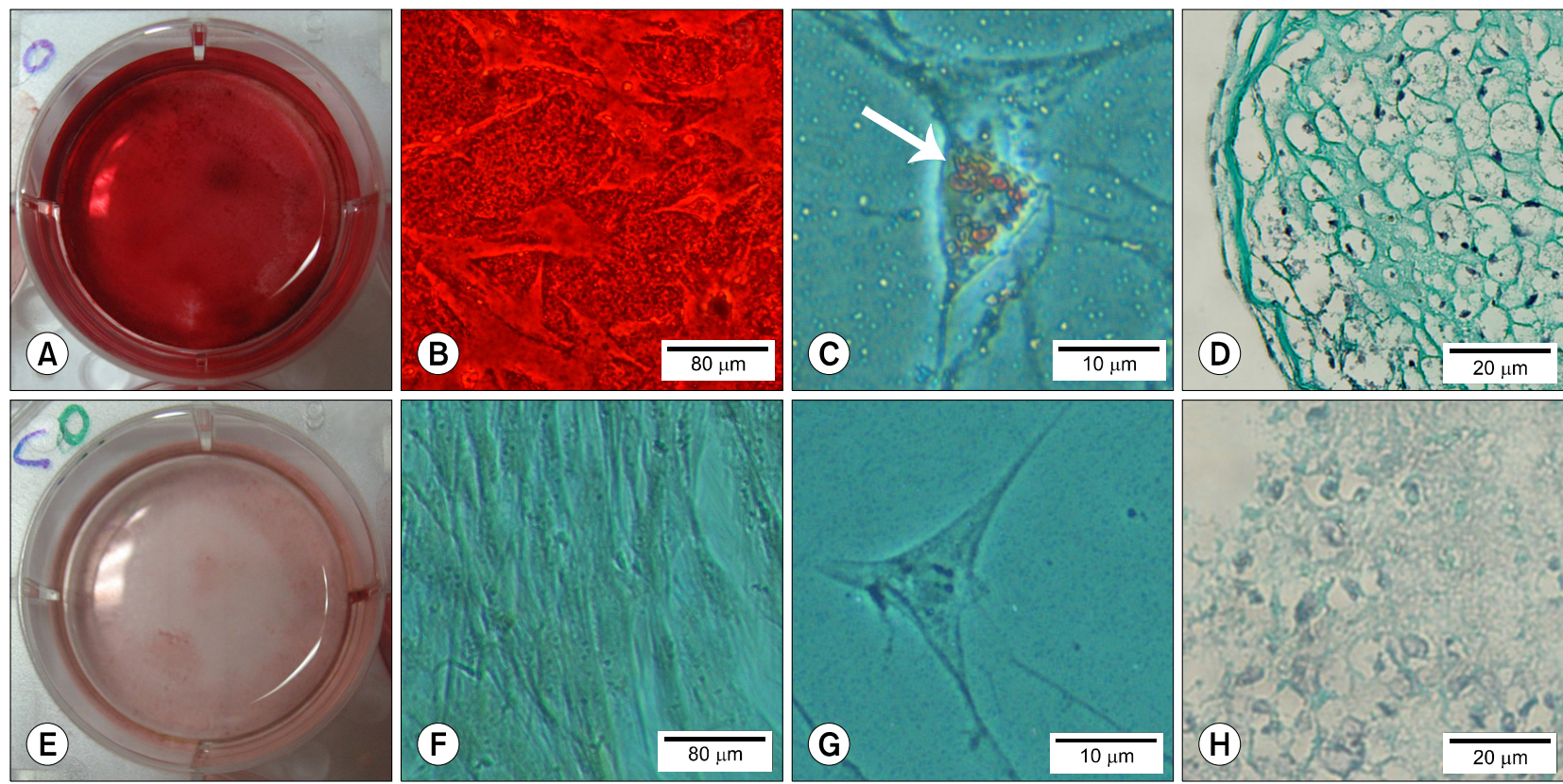

Fig. 3. Tri-lineage differentiation of equine BM-MSCs. Macroscopic $(A)$ and microscopic $(B, \times 40)$ view of Alizarin Red $S$ stained differentiated BM-MSCs. Oil Red O stained fat droplet in adipogenic treatment $(C, \times 400)$. Proteoglycans are stained with Alcian Blue in a pellet of chondrogenic differentiation group $(\mathrm{D}, \times 200)$. E-H are the control for A-D in which cultured with basal growth medium. 
mer sets for CD34 were also designed as intron-spanning primers giving rise to different PCR fragments from DNA and cDNA.

Observation of PCR products of undifferentiated P3 MSCs from each horse revealed that they expressed CD29, CD44, CD90, and MHC I. However, they did not showed expression of CD34, CD105 (hematopoietic marker) and MHC-II (Fig. 4A).

Expression of embryonic stemness genes at mRNA and/or protein levels: mRNA expression analysis of Nanog, Oct-4 and Sox-2 in P3 cells showed that the cells express only Sox-2 as a pluripotentcy marker (Fig. 4B and
4C).

Immunocytochemical analysis of all samples was done to investigate the expression of SSEA-1, -3, -4 and Nanog at protein level. No expression of these mentioned markers was found in the cells. Groups were stained with DAB substrate in the presence of HRP-conjugated secondary antibody. Positive and negative controls were included in the immunostaining process of all markers (Fig. 5).

\section{Discussion}

In this study we succeeded to isolate and characterize
A

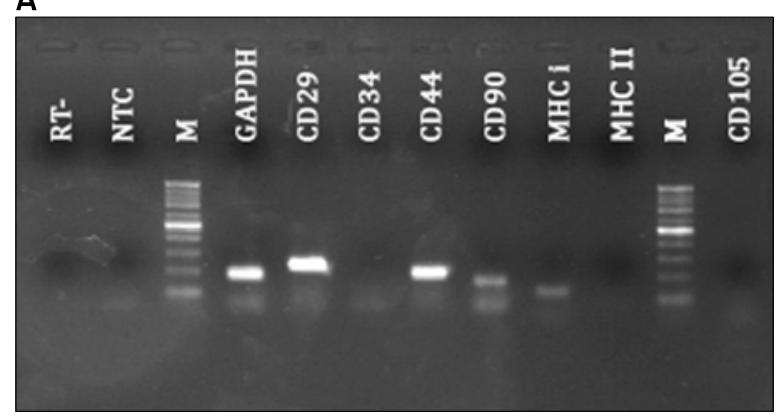

B

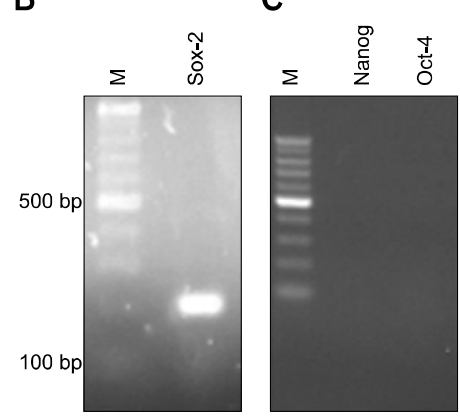

Fig. 4. Expression of surface and pluripotency markers of MSCs at mRNA level. RT-PCR showed the expression of GAPDH, CD29, CD44, CD90, MHC-I and lack of expression of CD34, CD105 and MHC-II. In NTC, dH2O was used for template as a control negative, and in RT sample, RNA was used instead of template to control genomic DNA contamination (A). The expression of SOX-2 gene was observed (B), and no expression of Oct-4 and Nanog was detected (C). M: 100 bp DNA ladder.

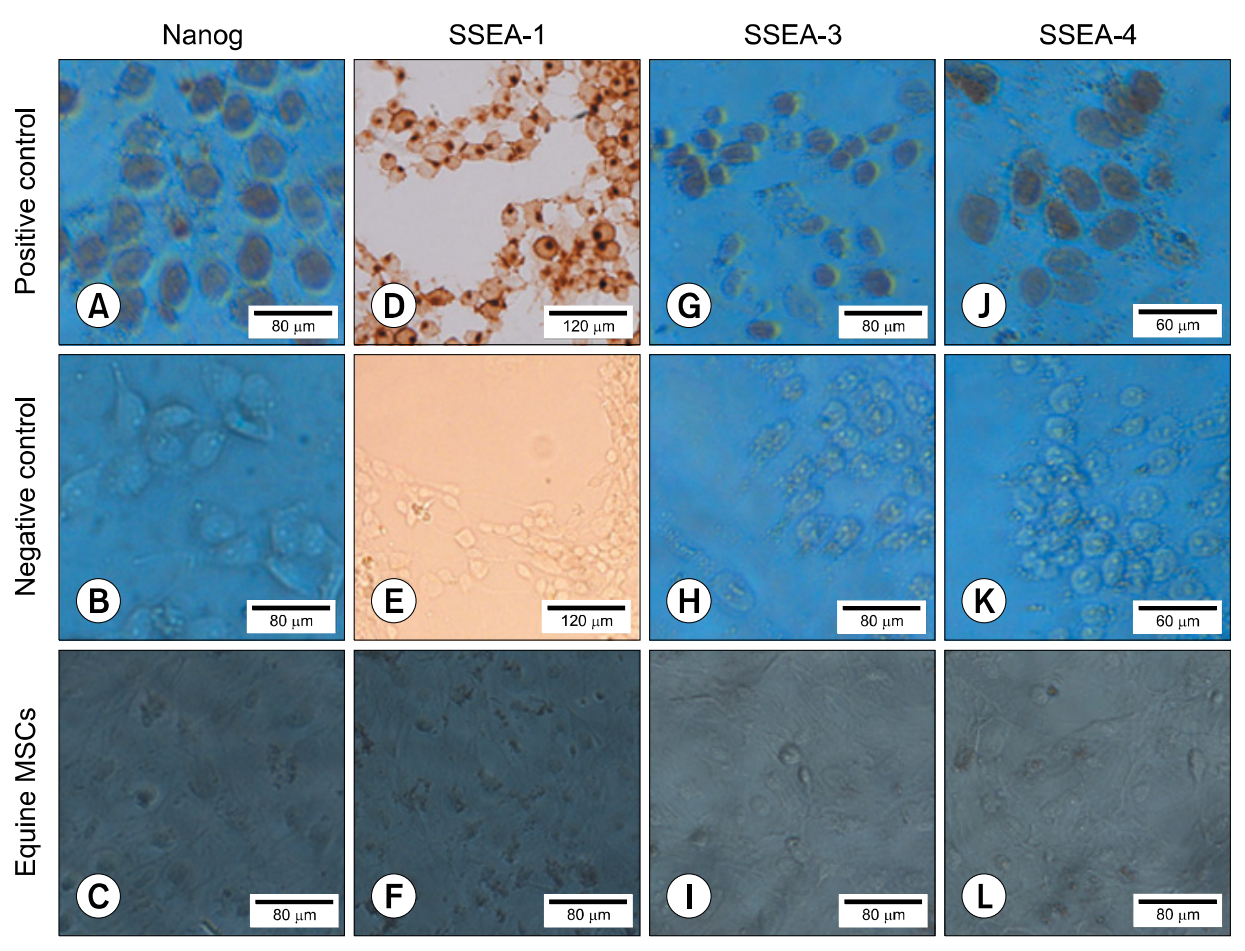

Fig. 5. Immunocytochemical analysis of pluripotency markers (Nanog, SSEA-1, -3 and -4 ) in equine MSCs at passage 3. The first row belongs to the positive control samples (A, G and J: NTERA2 cell line, and D: P19 cell line); the cells at the second row $(\mathrm{B}, \mathrm{E}, \mathrm{H}$ and $\mathrm{K})$ are the same cells of first row without using secondary antibody, and the third row cells (C, $\mathrm{F}, \mathrm{I}$ and $\mathrm{L}$ ) are equine MSCs at $\mathrm{P} 3$. No expression of pluripotency markers was found in equine MSCs. 
equine BM-MSCs. The isolated cells were fibroblast-like in shape, were attached to the culture dish and they expressed putative equine MSCs markers including CD29, CD44, CD90 and MHC-I and had no expression of CD34 and MHC-II (3). These cells properly differentiated to three osteogenic, adipogenic and chondrogenic lineages under specific differentiating mediums. Embryonic and pluripotency markers such as SOX-2 were detected at RNA level, but no expression was found for SSEA-1, -3, -4 and Nanog at protein level. The average of population doubling time (PDT) of cells during three passages was 62.07 hours and the $\mathrm{PE} \%$ was $8.67 \%$.

The plastic-adherence ability of MSCs is a general feature (3). MSCs population was heterogeneous in morphology at first passage. The heterogeneity degree of cells was decreased in later passages and fibroblast-like cells with two narrow ends were dominant in agreement with previous study (23).

Regarding growth characteristics, the lag phase (2 days) probably is due to stress of centrifugation and trypsinization of cells before the culture in 12-well plates. This lag time is similar to the results reported by Baghban Eslaminejad et al. (24). However, Lange-Consiglio et al. (25) reported 6 days for lag phase of BM-MSCs and less than 24 hours for adipose-derived MSCs (AMSCs). Finally, they found that the growth rate of AMSCs is higher than BM-MSCs. Moreover, Alipour ae al. (26) observed 3 days for lag time and 8 days for log phase of AMSCs. It seems that the growth rate of AMSCs is more than BM-MSCs. Moreover, different log phase of BM-MSCs in different studies might show that cells with different characteristics, at least regarding growth rate capabilities, have been isolated in these studies.

Assessment of colony forming unit ( $\mathrm{PE} \%)$, as one of the MSCs ability (27) which indicates their self-renewal capacity and quality of cell preparations (28), was $8.67 \%$ in 12 days. Lovati et al. (29) and Bourzac et al. (30) calculated $42 \%$ and $32 \%$ for equine BM-MSCs in 28 days, respectively. The difference is probably due to the time for colony formation or different characteristics of isolated cells. In addition, it has been shown that the number of colonies is affected by cell isolation method (30). Based on colony formation assay, it seems that BM-MSCs have more self-renewal capacity than AMSCs, as Alipour et al. (26) reported 5.5\% PE for AMSCs. Population doubling time (PDT) which assay cell expansion in vitro (31), was decreased with increasing the passage numbers. Vidal et al. (23) and Burk et al. (32) observed 33.6 and 98 hours for PDT of BM-MSCs, respectively. Ranera et al. (33) reported 59 hours of PDT for equine BM-MSCs and 52 hours for AMSCs. In another study, PDT for equine AMSCs was between 40 to 46 hours (26). In addition to difference between species, the culture conditions, growth factors and cell seeding number are affecting PDT.

Differentiation of human and equine MSCs toward osteogenic, adipogenic and chondrogenic lineages under the influence of defined medium, is one of the minimal criteria for their confirmation $(3,34)$. In our study, BM-MSCs at P3 were differentiated to these three lineages similar to other studies $(29,35)$. This finding approves the multipotency of our isolated BM-MSCs.

The expression of specific CD markers for equine MSCs was examined by RT-PCR at the mRNA level. A comparative study showed that the mRNA level of equine CD markers, follows the same patterns of relevant protein expression, then in the lack of proper antibody, RT-PCR is a valuable alternative (36). Gene expression analysis of isolated cells at $\mathrm{P} 3$ confirmed a specific expression profile for BM-MSCs. Despite of CD29 and CD44 is not included in ISCT minimal criteria for BM-MSCs (34), but De Schauwer et al. (3) stated that these markers are also important for characterization of the equine MSCs (3). Sox-2 gene expression was also analyzed by RT-PCR as a pluripotency marker. Sox- 2 is an essential transcription factor in undifferentiated embryonic stem cells for maintaining pluripotency (37). Expression of sox-2 in our isolated cells is agreement with other studies which reported sox-2 expression at mRNA level for equine BM-, FAT- and Cord Blood- MSCs $(38,39)$. Marfe et al. (40) only reported 15\% expression of Sox-2 in equine blood-derived stem cells at protein level.

Expression of pluripotency markers in equine MSCs is some studies confirmed the expression of Oct-4 (as another critical transcription factor for self-renewal in undifferentiated embryonic stem cells) in equine MSCs at protein level (17-19), whereas other studies observed no expression in equine MSCs (15). There are also positive results for SSEA-1, -3, -4, TRA-1-60 and TRA-1-81 expression (as other embryonic markers) in equine MSCs $(17,18)$, but Guest et al. (15) reported no expression of these markers in equine MSCs. In this study, no expression of Nanog, SSEA-1, -3 and -4 was observed in equine MSCs at protein level. The used $\mathrm{mABs}$ and control cell lines in our study were belonged to human and mice. The lack of specific $\mathrm{mAB}$ and appropriate control group, probably play an important role in these negative results (3). Moreover, different results in various study might show that the isolated cell population in these studies are different each other with specific characteristics. So, identification and purification of specific cells using more 
techniques and markers are strongly suggested. The isolated cells in this study also did not expressed Nanog and Oct-4 mRNA. Nevertheless, Ranera et al. (38) and Violini et al. (39) showed the expression of Nanog using qRT-PCR, and Marfe et al. (40) showed that $15 \%$ of cells were able to express Nanog.

In conclusion, this study succeed to isolate and characterize equine BM-MSCs with detailed data regarding their growth characteristics, differentiation capacities, expression of specific genes and pluripotency stemness markers. The results show that isolated BM-MSCs have the minimal defined criteria of MSCs.

\section{Acknowledgments}

This work was financially supported by Ferdowsi University of Mashhad.

\section{Potential Conflict of Interest}

The authors have no conflicting financial interest.

\section{References}

1. Metsäranta M, Kujala UM, Pelliniemi L, Österman H, Aho $\mathrm{H}$, Vuorio E. Evidence for insufficient chondrocytic differentiation during repair of full-thickness defects of articular cartilage. Matrix Biol 1996;15:39-47

2. Paris DB, Stout TA. Equine embryos and embryonic stem cells: defining reliable markers of pluripotency. Theriogenology 2010;74:516-524

3. De Schauwer C, Meyer E, Van de Walle GR, Van Soom A. Markers of stemness in equine mesenchymal stem cells: a plea for uniformity. Theriogenology 2011;75:1431-1443

4. Taylor SE, Smith RK, Clegg PD. Mesenchymal stem cell therapy in equine musculoskeletal disease: scientific fact or clinical fiction? Equine Vet J 2007;39:172-180

5. Frisbie DD, Kawcak CE, Werpy NM, McIlwraith CW. Evaluation of bone marrow derived stem cells and adipose derived stromal vascular fraction for treatment of osteoarthitis using an equine experimental model. USA, Texas, AAEP Proceedings 2006. 420-421

6. Koch TG, Betts DH. Stem cell therapy for joint problems using the horse as a clinically relevant animal model. Expert Opin Biol Ther 2007;7:1621-1626

7. Ahern BJ, Parvizi J, Boston R, Schaer TP. Preclinical animal models in single site cartilage defect testing: a systematic review. Osteoarthritis Cartilage 2009;17:705-713

8. Smith RK, Webbon PM. Harnessing the stem cell for the treatment of tendon injuries: heralding a new dawn? $\mathrm{Br} \mathrm{J}$ Sports Med 2005;39:582-584

9. Ibrahim S, Saunders K, Kydd JH, Lunn DP, Steinbach F. Screening of anti-human leukocyte monoclonal antibodies for reactivity with equine leukocytes. Vet Immunol Immunopathol 2007;119:63-80
10. Committee CTGTA. Cellular products for joint surface repair-Briefing document. 2005.

11. Ribitsch I, Burk J, Delling U, Gei $\beta$ ler C, Gittel C, Jülke $\mathrm{H}$, Brehm W. Basic science and clinical application of stem cells in veterinary medicine. Adv Biochem Eng Biotechnol 2010;123:219-263

12. Lakshmipathy U, Verfaillie C. Stem cell plasticity. Blood Rev 2005;19:29-38

13. Ryan JM, Barry FP, Murphy JM, Mahon BP. Mesenchymal stem cells avoid allogeneic rejection. J Inflamm (Lond) 2005;2:8

14. Guest DJ, Smith MR, Allen WR. Monitoring the fate of autologous and allogeneic mesenchymal progenitor cells injected into the superficial digital flexor tendon of horses: preliminary study. Equine Vet J 2008;40:178-181

15. Guest DJ, Ousey JC, Smith MR. Defining the expression of marker genes in equine mesenchymal stromal cells. Stem Cells Cloning 2008;1:1-9

16. Horwitz EM, Le Blanc K, Dominici M, Mueller I, Slaper-Cortenbach I, Marini FC, Deans RJ, Krause DS, Keating A; International Society for Cellular Therapy. Clarification of the nomenclature for MSC: the international society for cellular therapy position statement. Cytotherapy 2005;7:393-395

17. Hoynowski SM, Fry MM, Gardner BM, Leming MT, Tucker JR, Black L, Sand T, Mitchell KE. Characterization and differentiation of equine umbilical cord-derived matrix cells. Biochem Biophys Res Commun 2007;362:347-353

18. Li X, Zhou SG, Imreh MP, Ahrlund-Richter L, Allen WR. Horse embryonic stem cell lines from the proliferation of inner cell mass cells. Stem Cells Dev 2006;15:523-531

19. Reed SA, Johnson SE. Equine umbilical cord blood contains a population of stem cells that express Oct4 and differentiate into mesodermal and endodermal cell types. J Cell Physiol 2008;215:329-336

20. Reed SA, Johnson SE. Refinement of culture conditions for maintenance of undifferentiated equine umbilical cord blood stem cells. J Equine Vet Sci 2012;32:360-366

21. Lange C, Bassler P, Lioznov MV, Bruns H, Kluth D, Zander AR, Fiegel HC. Liver-specific gene expression in mesenchymal stem cells is induced by liver cells. World J Gastroenterol 2005;11:4497-4504

22. Yoon YS, Wecker A, Heyd L, Park JS, Tkebuchava T, Kusano K, Hanley A, Scadova H, Qin G, Cha DH, Johnson KL, Aikawa R, Asahara T, Losordo DW. Clonally expanded novel multipotent stem cells from human bone marrow regenerate myocardium after myocardial infarction. J Clin Invest 2005;115:326-338

23. Vidal MA, Kilroy GE, Johnson JR, Lopez MJ, Moore RM, Gimble JM. Cell growth characteristics and differentiation frequency of adherent equine bone marrow-derived mesenchymal stromal cells: adipogenic and osteogenic capacity. Vet Surg 2006;35:601-610

24. Baghaban Eslaminejad MR, Taghiyar L, Dehghan MM, Falahi F, Kazemi Mehrjerdi H. Equine marrow-derived mesenchymal stem cells: isolation, differentiation and cul- 
ture optimization. Iran J Vet Res 2009;10:1-11

25. Lange-Consiglio A, Corradetti B, Meucci A, Perego R, Bizzaro D, Cremonesi F. Characteristics of equine mesenchymal stem cells derived from amnion and bone marrow: in vitro proliferative and multilineage potential assessment. Equine Vet J 2013;45:737-744

26. Alipour F, Parham A, Kazemi Mehrjerdi H, Dehghani H. Equine adipose-derived mesenchymal stem cells: phenotype and growth characteristics, gene expression profile and differentiation potentials. Cell J 2015;16:456-465

27. Prockop DJ. Marrow stromal cells as stem cells for nonhematopoietic tissues. Science 1997;276:71-74

28. Mensing N, Gasse H, Hambruch N, Haeger JD, Pfarrer C, Staszyk C. Isolation and characterization of multipotent mesenchymal stromal cells from the gingiva and the periodontal ligament of the horse. BMC Vet Res 2011;7:42

29. Lovati AB, Corradetti B, Lange Consiglio A, Recordati C, Bonacina E, Bizzaro D, Cremonesi F. Comparison of equine bone marrow-, umbilical cord matrix and amniotic fluid-derived progenitor cells. Vet Res Commun 2011; 35:103-121

30. Bourzac C, Smith LC, Vincent P, Beauchamp G, Lavoie JP, Laverty $\mathrm{S}$. Isolation of equine bone marrow-derived mesenchymal stem cells: a comparison between three protocols. Equine Vet J 2010;42:519-527

31. Baghaban Eslaminejad M, Mardpour S, Ebrahimi M. Growth kinetics and in vitro aging of mesenchymal stem cells isolated from rat adipose versus bone marrow tissues. Iran J Vet Surg 2008;3:9-20

32. Burk J, Ribitsch I, Gittel C, Juelke H, Kasper C, Staszyk $\mathrm{C}$, Brehm W. Growth and differentiation characteristics of equine mesenchymal stromal cells derived from different sources. Vet J 2013;195:98-106

33. Ranera B, Ordovás L, Lyahyai J, Bernal ML, Fernandes F, Remacha AR, Romero A, Vázquez FJ, Osta R, Cons C, Varona L, Zaragoza P, Martín-Burriel I, Rodellar C.
Comparative study of equine bone marrow and adipose tissue-derived mesenchymal stromal cells. Equine Vet J 2012;44:33-42

34. Dominici M, Le Blanc K, Mueller I, Slaper-Cortenbach I, Marini F, Krause D, Deans R, Keating A, Prockop Dj, Horwitz E. Minimal criteria for defining multipotent mesenchymal stromal cells. The international society for cellular therapy position statement. Cytotherapy 2006;8:315317

35. Koch TG, Heerkens T, Thomsen PD, Betts DH. Isolation of mesenchymal stem cells from equine umbilical cord blood. BMC Biotechnol 2007;7:26

36. Radcliffe CH, Flaminio MJ, Fortier LA. Temporal analysis of equine bone marrow aspirate during establishment of putative mesenchymal progenitor cell populations. Stem Cells Dev 2010;19:269-282

37. Masui S, Nakatake Y, Toyooka Y, Shimosato D, Yagi R, Takahashi K, Okochi H, Okuda A, Matoba R, Sharov AA, Ko MS, Niwa H. Pluripotency governed by Sox2 via regulation of Oct3/4 expression in mouse embryonic stem cells. Nat Cell Biol 2007;9:625-635

38. Ranera B, Remacha AR, Álvarez-Arguedas S, Romero A, Vázquez FJ, Zaragoza P, Martín-Burriel I, Rodellar C. Effect of hypoxia on equine mesenchymal stem cells derived from bone marrow and adipose tissue. BMC Vet Res 2012;8:142

39. Violini S, Ramelli P, Pisani LF, Gorni C, Mariani P. Horse bone marrow mesenchymal stem cells express embryo stem cell markers and show the ability for tenogenic differentiation by in vitro exposure to BMP-12. BMC Cell Biol 2009;10:29

40. Marfe G, Massaro-Giordano M, Ranalli M, Cozzoli E, Di Stefano C, Malafoglia V, Polettini M, Gambacurta A. Blood derived stem cells: an ameliorative therapy in veterinary ophthalmology. J Cell Physiol 2012;227:1250-1256 